\title{
Analyzing the trend in thermal discomfort and other bioclimatic indices at Kolasib, Mizoram
}

\author{
S. SAHA, D. CHAKRABORTY ${ }^{1}$, S. B. SINGH, S. CHOWDHURY, E.K. SYIEM, S.K. DUTTA, \\ LUNGMUANA, B.U. CHOUDHURY ${ }^{1}$, T. BOOPATHI, A.R. SINGH, Y. RAMAKRISHNA and A. ROY ${ }^{1}$ \\ ICAR Research Complex for NEH Region, Mizoram centre, Kolasib, Mizoram - 796081 \\ ${ }^{1}$ ICAR Research Complex for NEH Region, Umiam, Meghalaya \\ Email:sauravs.saha@gmail.com
}

\begin{abstract}
Monthly weather variables of Kolasib for past three decades were analyzed to detect the existing trend in relation to the thermal discomfort for tribal denizen in the north-eastern Indian state of Mizoram. The significant rising trend in seasonal wetness during the monsoon months was prominent, with the concomitant rise in winter dryness. The increasing trend in annual air temperature was also significant. The significant rise in Compensated Summer Ombrothermic Index (COSi) confirmed that the rising trend in monsoonal rainfall overshadowed the subsequent rise in average annual air temperature during May to September. Finally, our present study concluded the increasing possibility of degree of suffering from thermal discomfort for the residents of the Kolasib and adjacent region during the winter (viz. February) and summer monsoon months (viz May-June) in near future.
\end{abstract}

Keywords: Thermal discomfort, air temperature, Compensated Summer Ombrothermic Index, Mizoram

The North Eastern Indian state of Mizoram is a storehouse of ethnic beauty, high species diversity and immense natural resources with its diverse landscape in hilly terrains and monsoon-dominated climate system. The physical inaccessibility of this sparsely populated state is still suffering from underdevelopment and poor infrastructure. At present, climate change is gaining attention as a significant strategic, social and environmental issue felt by the majority of governments and scientists which may leave significant impact on the native population, natural beauty and unexplored natural resources of the North East Indian states. The vital fragile ecosystems and subsistence agricultural sector of these North East Indian states are under a serious risk due to the immense pressure from depleting natural resources from extensive anthropogenic intervention induced stresses like massive deforestation, unscientific way of cultivation/management of land, frequent landslides, increasing urbanization activities etc (Bharali and Khan, 2011).

Our present literature survey found the high spatiotemporal variability in the scanty reports available to describe the existing trends for different recorded weather variables which were analyzed across the scattered patches of different NE Indian states other than the sole Mizoram state. Das et al, (2009) addressed the role of significant erratic annual rainfall received for imposing serious threats of agricultural drought in the different NE Indian states. Jhajharia and Singh (2011) showed the spatial variability in the trends of maximum \& minimum temperature across the NE Indian state of Assam. Choudhury et al, (2012) observed a significant rising trend in maximum temperature with nonsignificant decreasing trend in minimum temperature and non-significant increasing trend in annual rainfall at the mid altitude of Meghalaya. Jain and Kumar (2012) observed a non-significant increasing trend in annual rainfall with a significant rise in annual air temperature for the NMMT hydro-meteorological subdivision (Nagaland, Manipur, Mizoram and Tripura) in NE India using the daily gridded rainfall data $\left(1^{\circ} \times 1^{\circ}\right)$ of the India Meteorological Department (IMD) with a significant reduction in rainy days (Saikia et al., 2013). In contrast, data records from the ground meteorological observatory confirmed no trend in mean monthly, seasonal, and annual rainfall for the same region (Jain et al., 2013).

In the present study various bioclimatic indices viz. Emberger pluviothermic quotient (Q), Box's moisture index $(\mathrm{M} i)$, Thermicity index $(\mathrm{T} i)$, Ombrothermic index $(\mathrm{O} i)$ Continentality index $(\mathrm{C} i)$ and Standardized precipitation index (SPI) were calculated and trends have been analyzed. 


\section{MATERIALS AND METHOD}

The long term rainfall (1980-2014) and temperature (1986-2014) data recorded at ground observatory installed at ICAR-NEH, Mizoram centre (Kolasib: latitude: $24^{\circ} 12^{\prime} 77^{\prime \prime}$ $\mathrm{N}$; longitude: $92^{\circ} 40^{\prime} 52^{\prime \prime} \mathrm{E}$; elevation: $622.1 \mathrm{~m}$ from mean sea level) were analyzed. The seasonal trends in air temperature and rainfall were analyzed for four distinct seasons viz. January-February (winter), March-May (premonsoon), June-September (monsoon)and October December (post monsoon). The temporal variability in monthly precipitation values (1980-2014) were used to calculate SPI values at 1 month, 3 month and 6 month timescale (McKee et al., 1993). For any specific location, the SPI was defined on each of the time scales as the difference between precipitation on the time series (xi) and the mean value $\mu$, divided by the standard deviation $(\delta)$ i.e.

$\mathrm{SPI}=(\mathrm{xi}-\mu) / \delta$

From the available dataset potential evapotranspiration (PET) were calculated for last 28 years (Thornthwaite, 1948), followed by the year wise computation of standardized precipitation evapotranspiration index (SPEI) from the difference between potential evapotranspiration and precipitation in the similar way as described by Yu et al. (2014). In addition, the following bioclimatic indices were calculated from the recorded dataset.

Pluviothermic Quotient (Q) determines the degree of moistness as given by Attorre et al. (2007)

$\mathrm{Q}=2000 \mathrm{P} /\left(\mathrm{Tmax}_{\mathrm{h}}^{2}-\mathrm{T} \min _{\mathrm{c}}{ }^{2}\right)$

Where:

$\mathrm{P}=$ mean annual precipitation $(\mathrm{mm}) ; \mathrm{T} \max _{\mathrm{h}}=$ mean maximum temperature of the hottest month $\left({ }^{\circ} \mathrm{C}\right) ; \mathrm{T} \min _{\mathrm{c}}=$ mean minimum temperature of the coldest month $\left({ }^{\circ} \mathrm{C}\right)$

Thermicity index (Ti; Attorre et al., 2007) represents the thermal regime

$\mathrm{Ti}=10\left(\mathrm{~T}_{\text {mean }}+\mathrm{Tmin}_{\mathrm{c}}+\mathrm{T} \max _{\mathrm{h}}\right)$

Continentality index (Ci; Attorre et al., 2007) also indicates the thermal regime

$\mathrm{Ci}=\left(\mathrm{T} \max _{\mathrm{h}}-\mathrm{T} \min _{\mathrm{c}}\right)$

Box's moisture index (Mi; Box, 1981) is the ratio of precipitation to potential evapotranspiration (PET; Thornthwaite method)

$\mathrm{Mi}=(\mathrm{P} / \mathrm{PET})$
Ombrothermic index (Oi; Rivas-Martinez, 1996)

$\mathrm{O} i=10(\mathrm{YPP} / \mathrm{YPT})$

Where:

YPP $=$ sum of the average precipitation of months whose average temperature is $>0{ }^{\circ} \mathrm{C}$, YPT $=$ sum of the average temperature of months whose average temperature is $>0{ }^{\circ} \mathrm{C}$.

Compensated summer ombrothermic index (COSi) was calculated using the rainfall and temperature from May to September (Rivas-Martinez, 1996)

$\operatorname{CoS} i=\frac{\sum_{\text {Sept }}^{\mathrm{May}^{\mathrm{P}}}}{\sum_{\text {Sept }}^{\mathrm{May}}}$

Temperature humidity index (TDI; Thom, 1959) was calculated using monthly temperature $\left({ }^{\circ} \mathrm{C}\right)$ and relative humidity (RH in \%) followings:

$\mathrm{TDI}=\mathrm{T}_{\text {mean }}-(0.55-0.0055 \mathrm{RH})\left(\mathrm{T}_{\text {mean }}-14.5\right)$

The degree of thermal discomfort was characterized by TDI based on the recorded temperature and relative humidity observations. The detailed ranges of TDI based human comfort classification are displayed in Table 1 (Giles et al., 1990). The temporal trend for the year wise calculated values of SPI, SPEI and the above-mentioned bioclimatic indices were assessed by nonparametric Man Kendall test for monotonic trend analysis. Amplitudnal changes were expressed in terms of Mann Kendall test derived $Z$ values. Theil-Sen's estimator $(\beta)$ was calculated to deduce the rate of changes in seasonal rainfall as follows:

$\beta=\operatorname{Median}[(x j-x i) /(j-i)]$ for all $i<j$

Where, $x j$ and $x i$ are rainfall data points at times $j$ and $i$, respectively.

\section{RESULTS AND DISCUSSION}

\section{Trends in temperature}

A significant increase in annual average air temperature were recorded $(\mathrm{P}<0.05)$ at Kolasib (Mizoram) for last 28 years (Fig 1). The winter month of February was found to becoming warmer at Kolasib, due to significant increase in both maximum and minimum air temperature, along with significant rise in monthly minimum temperature during March. Both the mean monthly maxima and minima of air temperature values showed a non-significant increasing trend during the rest part of the year (Table 2). Seasonal analysis for changing temperature trend further affirmed the 


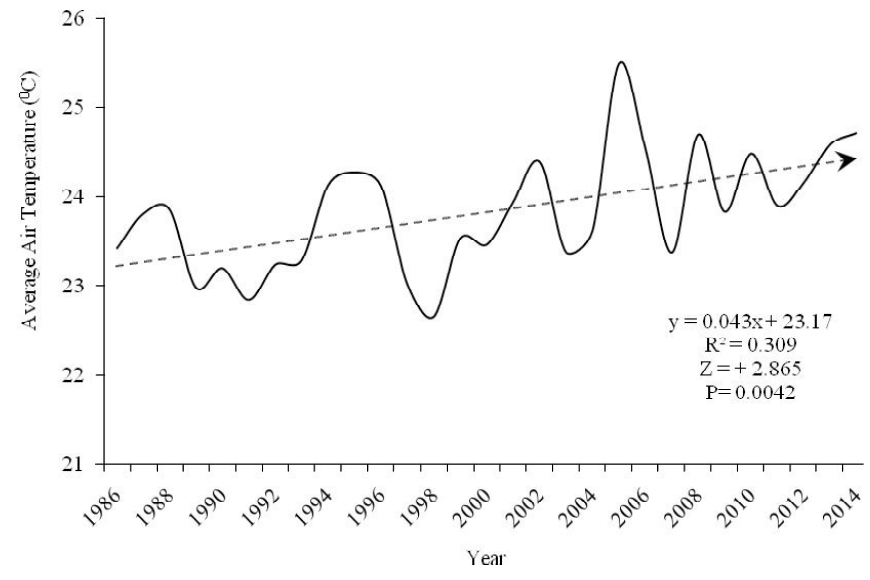

Fig 1: Average annual air temperature trend (1986-2014) at non-significant rising trend in maximum and minimum air temperature.

\section{Trends in rainfall, SPI and SPEI}

Monthly rainfall trend analysis showed an abrupt increase in 1 month SPI during August at Kolasib, with lower annual variability (Saha et al., 2015). This increase indicated by a significant rise in 1 month August SPI, followed by significant increase in 3 month SPI values for September and October, resulted in prominent increasing trend in 6 months SPI values for September, October, November and December. The results confirmed that Kolasib is becoming wetter during last 35 year for experiencing more monsoonal rainfall in August (Table 2).

The temporal variation in the monthly SPEI values recorded in the existing agro-ecosystem of the subtropical humid condition of Kolasib (Table 2). The pattern of the existing environmental change suggested a significant rise in 3 months SPEI from July to October due to increasing moistness which coincides with the dominant jhum cultivation period (May to September) across the Mizoram state. Consequently, the negative trend of 3 months SPEI values during January and February month affirmed the increasing dryness during the post monsoon and winter months. Rabi agriculture in the NE Indian states of Mizoram maybe adversely affected due to this environmental change driven increasing water scarcity problem in near future.

Winter months (January and February) accounts the high rainfall variability at Kolasib. Therefore the significant reduction trend in 1 month SPI during the month of February was not sufficient enough to conclude the reducing trend of winter rainfall (January and February) at Koasib. But a significant reduction in 3 months SPI as well as the SPEI values denotes the increasing dryness during the winter
Table 1: Detailed categorization of thermal discomfort conditions according to Thom's Thermal Discomfort Index (TDI)

\begin{tabular}{lr}
\hline Condition & Thermal Discomfort Index (TDI) \\
\hline No discomfort & $<21$ \\
Under 50\% of population feels discomfort & $21-24$ \\
Over 50\% of population feels discomfort & $25-27$ \\
Most of population suffers discomfort & $28-29$ \\
Everyone feels stress & $30-32$ \\
State of medical emergency & $>32$ \\
\hline
\end{tabular}

months (Table 2). Seasonal rainfall trend analysis also affirmed the similar findings of increasing moistness/wetness during the monsoon month and more dryness during the winter season (Table 3). On an average Koasib experienced a non significant rising trend in annual rainfall. The Theil-Sen's estimator indicated the rate of reduction in winter rainfall by $1.8 \mathrm{~mm} \mathrm{decade}^{-1}$ along with a rise in monsoon rainfall @ 25.6 mm decade ${ }^{-1}$.

\section{Trends in bioclimatic indices}

Trends in different bioclimatic indices showed an increasing trend for last 28 years (Table 4 ). The significant increase in Ti often accounted for increasing trend yearly mean temperature along with significant reduction in the mean of minimum temperature of the winter months. The difference between the mean temperature of the hottest and the coldest month was represented by $\mathrm{C} i$ which showed non-significant increasing trend along with increasing $\mathrm{M} i$ due to enhanced annual wetness due to increasing premonsoon and monsoonal rainfall.

The significant increase in $\mathrm{O} i$ indicates the dominancy of the increasing magnitude of the average annual precipitation over the average annual temperature increase. Moreover the trend became prominent, while $\operatorname{COS} i$ was calculated for major rainfall receiving months (May to September). The significant increasing trend in the $\mathrm{COS} i$ indicated that the increasing trend of monthly average temperature was often overshadowed by the increasing wetness trend during the major rainfall receiving months.

\section{Thermal discomfort index (TDI)}

Thermal comfort is the condition of mind that expresses satisfaction with the thermal environment. The winter months signifies almost no thermal discomfort due to the lower TDI values $(<21)$ (Table 5). At Kolasib, according to the TDI, less than $50 \%$ of population may feel discomfort 
Table 2: $Z$ values (monthly) from MK trend analysis of maximum air temperature, minimum air temperature, SPI and SPEI values for different time scale at Kolasib (1986-2014) (Note: $\left.{ }^{\wedge} \mathrm{P}<0.1 ; * \mathrm{P}<0.05 ; * * \mathrm{P}<0.01\right)$

\begin{tabular}{|c|c|c|c|c|c|c|c|c|}
\hline \multirow[t]{2}{*}{ Timescale } & \multirow{2}{*}{$\begin{array}{l}\text { Maximum } \\
\text { air } \\
\text { temperature }\end{array}$} & \multirow{2}{*}{$\begin{array}{c}\text { Minimum } \\
\text { air } \\
\text { temperature }\end{array}$} & \multicolumn{3}{|c|}{ SPI } & \multicolumn{3}{|c|}{ SPEI } \\
\hline & & & 1-month & 3-month & 6-month & 1-month & 3-month & 6-month \\
\hline January & +0.652 & +0.573 & -1.512 & $-2.123^{*}$ & $+2.654 * *$ & +0.891 & $-1.942^{\wedge}$ & +0.855 \\
\hline February & $+1.877^{\wedge}$ & $+2.925 * *$ & $-2.617 * *$ & $-2.418 * *$ & +0.756 & $-2.426 * *$ & $-2.611 * *$ & -1.193 \\
\hline March & +0.771 & $+2.332 *$ & -0.227 & -0.312 & -1.008 & +0.167 & +0.631 & -1.475 \\
\hline April & +1.304 & +0.909 & -0.966 & -0.753 & -1.038 & -0.201 & -0.227 & $-1.877^{\wedge}$ \\
\hline May & +0.771 & +1.107 & +0.801 & +0.460 & +0.496 & +1.641 & +1.247 & 0.063 \\
\hline June & +1.265 & +0.514 & +0.208 & +0.326 & +0.178 & +0.948 & +1.423 & +1.087 \\
\hline July & +0.277 & +1.087 & +0.741 & +0.979 & +0.682 & +0.672 & $+2.292 *$ & +1.363 \\
\hline August & +0.771 & +0.968 & $+3.039 * *$ & $+1.720^{\wedge}$ & +1.312 & $+2.273^{*}$ & $+2.253^{*}$ & $+2.153 *$ \\
\hline September & -0.02 & +0.198 & $+1.942^{\wedge}$ & $+2.076^{*}$ & $+1.928^{\wedge}$ & +1.186 & $+1.976^{*}$ & $+2.450 * *$ \\
\hline October & +0.356 & +1.344 & +0.104 & $+3.143^{*} *$ & $+2.120 *$ & -0.560 & $+2.193 *$ & $+2.352 *$ \\
\hline November & +0.375 & -0.059 & $-1.738^{\wedge}$ & +1.305 & $+1.972^{\wedge}$ & $-2.143^{*}$ & 0.139 & $+1.996^{*}$ \\
\hline December & +0.079 & +0.85 & -0.800 & -0.549 & $+1.927^{\wedge}$ & -0.704 & $-1.771^{\wedge}$ & +1.600 \\
\hline
\end{tabular}

Table 3: MK test derived $\mathrm{Z}$ values to detect the changes in seasonal temperature and rainfall pattern, with the Theil Sen's estimator to quantify the seasonal rainfall change (1980-2010) at Kolasib (Note:^ $\mathrm{P}<0.1 ;^{*} \mathrm{P}$ $<0.05 ; * * \mathrm{P}<0.01)$

\begin{tabular}{lcccc}
\hline Seasons & $\mathbf{Z}_{\text {Minimum }}$ & $\mathbf{Z}_{\text {Minimum }}$ & $\mathbf{Z}_{\text {Rainfall }}$ & $\begin{array}{c}\text { Seasonal } \\
\text { remperature } \\
\text { temperature } \\
\text { change } \\
\text { (mm/decade) }\end{array}$ \\
\hline Winter & +1.067 & +1.541 & $-2.82^{* *}$ & $-1.79^{* *}$ \\
Premonsoon & +1.462 & +1.324 & -0.059 & +7.23 \\
Monsoon & +0.494 & +0.652 & $+1.889^{\wedge}$ & $+25.59^{\wedge}$ \\
Postmonsoon & +0.296 & +1.008 & -0.92 & -0.79 \\
Annual & +1.442 & +1.205 & +1.482 & +30.11 \\
\hline
\end{tabular}

Table 4: $\mathrm{Z}$ values from MK trend analysis for the annual values of different bioclimatic indexes at Kolasib (1986-2014)

\begin{tabular}{lc}
\hline Indices & Z values \\
\hline Pluviothermic Quotient & $+1.821^{\wedge}$ \\
Ombrothermic Index & $+1.998^{*}$ \\
Compensated Summer Ombrothermic Index & $+2.757^{* *}$ \\
Continentality Index & +0.214 \\
Thermicity Index & $+2.070^{*}$ \\
Box’s moisture Index & +0.882 \\
\hline
\end{tabular}

Table 5: $M K$ test derived $Z$ values with the range of the monthly Temperature Humidity Index (TDI) values at Kolasib.

\begin{tabular}{lll}
\hline Months & TDI values & Z values \\
\hline January & $15.5-18.5$ & +0.88 \\
February & $16.3-21.2$ & $+1.73^{\wedge}$ \\
March & $17.2-24.3$ & $+2.03^{*}$ \\
April & $20.2-26.7$ & +1.08 \\
May & $22.1-27.1$ & $+1.67^{\wedge}$ \\
June & $23.9-26.8$ & $+2.12^{*}$ \\
July & $23.7-26.9$ & +1.28 \\
August & $23.6-26.5$ & +1.23 \\
September & $22.6-26.1$ & +0.48 \\
October & $19.7-25.8$ & +1.16 \\
November & $17.6-24.9$ & +0.42 \\
December & $16.8-23.6$ & +0.80 \\
\hline
\end{tabular}

during March and more than 50\% people may feel discomfort during April to October. We observed a steady increasing trend of thermal discomfort during the month of February, March, May and June at Kolasib. The suffering from increasing degree of thermal discomfort may increase due to adverse impact of inevitable projected environmental change and variability in North East India. 


\section{CONCLUSION}

Increasing temperature and reduced rainfall increased the degree of thermal discomfort during the month of February and March during last three decades, for the Mizo dwellers at Kolasib. The steady increasing trend in the average annual temperature along with average minimum and maximum temperature of the coldest month of the year resulted significant rise in Ti and thermal discomfort at June, without affecting the difference between annual mean temperature of the hottest and coldest month $(\mathrm{C} i)$. Moreover, the increased wetness during the monsoon months resulted in increasing trend in SPEI with a significant rise in annual values of $\mathrm{O} i$ and $\mathrm{COS} i$ at Kolasib.

\section{REFERENCES}

Das Anup, Ghosh, P.K., Choudhury, B.U., Patel, D.P., Munda, G.C., Ngachan, S. V. and Chowdhury, P. (2009). Climate change in northeast India: recent facts and events worry for agricultural management. In: "ISPRS Archives XXXVIII-8/W3 Workshop Proceedings: Impact of Climate Change on Agriculture”. pp. 32-37

Box, E.O. (1981). "Macroclimate and plant forms: An introduction to predictive modelling in phytogeography”. (Dr. W. Junk Publishers) 258 pp.

Brian D. Giles, Balafoutis, C.H. and Maheras, P. (1990). Too hot for comfort: the heat waves in Greece in 1987 and 1988. Int. J. Biomet., 34: 98-104

Choudhury B. U., Das, A., Ngachan, S.V., Slong, A., Bordoloi, L.J. and Chowdhury, P. (2012). Trend analysis of long term weathervariables in mid altitude Meghalaya, NorthEast India. J. Agril. Physics, 12(1): 12-22.

Thornthwaite C. W. (1948). An approach toward a rational classification of climate. Geog. Rev., 38 (1): 55 - 94

Jhajharia D. and Singh, V.P. (2011). Trends in temperature, diurnal temperature range and sunshine duration in Northeast India. Int. J. Climatol., 31: 1353-1367

Thom E.C.(1959). The discomfort index. Weather wise, 12(2): $57-60$
Attorre F., Alfo, M., Sanctis, M. De., Francesconia F. and Brunoa F. (2007). Comparison of interpolation methods for mapping climatic and bioclimatic variables at regional scale. Int. J. Climatol., 27: 1825-1843

Yu M., Li, Q., Hayes, M.J., Svobod M.D. and Heim, R.R. (2014). Are droughts becoming more frequent or severe in China based on the Standardized Precipitation Evapotranspiration Index: 1951-2010? Int. J. Climatol., 27: $1825-1843$

S. Rivas-Martinez (1996). Clasificac‘ýon Bioclim‘atica de la tierra. Folia Botanica Matritensis 16: 1-32

Bharali S. and Khan, M.L. (2011). Climate change and its impact on biodiversity; some management options for mitigation in Arunachal Pradesh. Current Sci., 101(7): 855-860.

Saha S., Chakraborty, D., Choudhury, B.U., Singh, S.B., Chinza, N., Lalzarliana, C., Dutta, S.K., Chowdhury, S., Boopathi, T., Lungmuana, Singh, A.R., Ngachan, S.V. (2015). Spatial variability in temporal trends of precipitation \& its impact on the agricultural scenario of the North Eastern Indian state of Mizoram. Current Sci. (Accepted)

Jain S.K. and Kumar, V. (2012). Trend analysis of rainfall and temperature data for India. Current Sci., 102(1): 37-49

Jain S.K., Kumar, V. and Saharia, M. (2013). Analysis of rainfall and temperature trends in northeast India. Int. J. Climatol., 33(4): 968-978

McKee T. B., Doesken, N.J. and Kleist, J. (1993). The relationship of drought frequency and duration to time scales. In: "Proceedings of the IX Conference on Applied Climatology”.pp. 179-184(American Meteorological Society: Boston, MA)

Saikia U., Goswami, B., Rajkhowa, D.J., Venkatesh, A., Ramachandran, K., Rao, V.U.M., Venkateswarlu, B. and Ngachan, S.V.(2013). Shift in monsoon rainfall pattern in the North Eastern region of India post 1991. J. Agromet., 15 (2): 162-164 